\title{
EFEITO DA INCLUSÃO DE DIFERENTES TIPOS DE ÓLEO NA DIETA DE VARRÕES SOBRE A QUALIDADE DO SÊMEN "IN NATURA"
}

\author{
Effect of the inclusion of different types of oil in the diet of boars \\ on the quality of semen in natura
}

\author{
Silvio Luiz de Oliveira ${ }^{1}$, Elias Tadeu Fialho², Luis David Solis Murgas ${ }^{3}$, José Augusto de Freitas², \\ Rilke Tadeu Fonseca de Freitas ${ }^{2}$, Márcio Gilberto Zangeronimo ${ }^{4}$
}

\begin{abstract}
RESUMO
O experimento foi realizado no Departamento de Zootecnia da Universidade Federal de Lavras-MG, com o objetivo de avaliar o desempenho reprodutivo de varrões alimentados com rações suplementadas com diferentes tipos de óleos como fontes de ácidos graxos essenciais. Foram utilizados 24 suínos híbridos (AGPIC 337), machos inteiros, com peso inicial médio de $152,7 \mathrm{~kg}$, em um delineamento experimental em blocos ao acaso, com quatro tratamentos $(\mathrm{T} 1=$ controle; $\mathrm{T} 2=3 \%$ óleo de linhaça; $\mathrm{T} 3=3 \%$ óleo comercial PUFA $^{\circledR}$ e T4 $=3 \%$ de óleo de peixe) e seis repetições, com um animal por unidade experimental. As rações foram isoenergéticas e isoprotéicas, formuladas à base de milho e farelo de soja. As variáveis analisadas foram parâmetros seminais como motilidade, vigor, volume, concentração, número total de células e anomalias espermáticas, avaliadas entre a quarta e a décima primeira semana do início do fornecimento das rações aos animais. Não houve diferenças significativas entre os tratamentos para motilidade, concentração e anormalidades espermáticas totais $(\mathrm{P}>0,05)$, exceto para alteração de cauda $(\mathrm{P}<0,05)$, cuja suplementação com óleo de peixe apresentou pior resultado. Por outro lado, o vigor espermático foi significativamente maior para o óleo de peixe $(\mathrm{P}<0,05)$. Para volume e número total de espermatozóides no ejaculado, melhores resultados foram obtidos com o óleo comercial $\mathrm{PUFA}{ }^{\circledR}(\mathrm{P}<0,05)$. Conclui-se que, nas avaliações do sêmen in natura, o uso de óleo comercial PUFA ${ }^{\circledR}$ e óleo de peixe nas rações de varrões demonstrou ser mais eficiente para a produção de células espermáticas e para a viabilidade destas células, respectivamente.
\end{abstract}

Termos para indexação: Ácidos graxos, características seminais, nutrição, reprodução, suínos.

\begin{abstract}
The experiment was conducted at Animal Science Department of University of Lavras-MG, with the objective to evaluate the quality of semem in natura of boars fed with rations supplemented with different sources of oils as sources of essential fat acids. Twenty four hybrid boars (AGPIC 337) were used, with initial average weight of $152,7 \mathrm{~kg}$, assigned into a randomized complete blocks design, with four treatments $\left(\mathrm{T} 1=\right.$ control; $\mathrm{T} 2=3 \%$ linseed oil; T3 $=3 \%$ commercial oil PUFA ${ }^{\circledR}$ and T4 $=3 \%$ of fish oil) and six repetitions, being each animal as a experimental unit. The diets were isoenergetics and isoproteics, formulated with corn and soybean meal. The analyzed variables were seminal parameters as mobility, vigor, volume, concentration, total number of cells and anomalies spermatic, valued between four and eleventh week of the experimental period. The data showed any significant differences among the treatments for the motility, concentration and total anomalies spermatic $(\mathrm{P}>0,05)$, except for alteration of tail $(\mathrm{P}<0,05)$, whose supplementation with fish oil shown worse results. Also the spermatic vigor were significantly higher $(\mathrm{P}<0.05)$ for the boars fed rations with fish oil suplementation. The volume and total number of spermatozoid in the ejaculate, showed best results for those boars fed rations with commercial oil PUFA ${ }^{\circledR}(\mathrm{P}<0,05)$. It was conclude that, the quality of the semen in natura, for boars fed rations he supplemented with commercial oil PUFA ${ }^{\circledR}$ and the fish oil showed to be more efficient for the parameters spermatic cells production and cells viability in the young boars.
\end{abstract}

Index terms: Fat acids, seminal characteristics, nutrition, reproduction, swine.

(Recebido para publicação em 3 de junho de 2005 e aprovado em 20 de junho de 2006)

\section{INTRODUÇÃO}

Os índices reprodutivos em um plantel suinícola são extremamente importantes no que se refere à lucratividade neste setor. Com o avanço da técnica de inseminação artificial em suínos e sua comprovada eficiência em relação à monta natural, a busca por sêmen de melhor qualidade tem sido priorizada por inúmeros pesquisadores. Além das técnicas de processamento de sêmen, a manipulação da dieta também tem se mostrado uma importante ferramenta para maximizar a produtividade nesse sentido.

Os lipídeos são constituintes orgânicos importantes da ração dos suínos, não só pelos seus elevados valores energéticos, como também pelos ácidos graxos essenciais

${ }^{1}$ Médico Veterinário, Professor Substituto da Universidade Federal de Goiás - s3oliveira@yahoo.com

${ }^{2}$ Professores Titulares do Departamento de Zootecnia - Universidade Federal de Lavras/UFLA - Cx. P. 3037 - $37.200-000$ - Lavras, MG.

${ }^{3}$ Professor Titular do departamento de Medicina Veterinária - Universidade Federal de Lavras/UFLA - Cx. P. 3037 - 37.200-000 - Lavras, MG Ismurgas@ufla.br

${ }^{4}$ Médico Veterinário, Doutor em Nutrição de Monogástricos. 
contidos na fração lipídica dos alimentos naturais. Diversos trabalhos têm mostrado que a utilização de diferentes tipos de óleos na dieta exerce forte influência sobre as características seminais de varrões (MURGAS, 1999; ROOKE et al., 2001; STRZEZEK et al., 2004). De acordo com esses autores, a relação entre os ácidos graxos da série $\omega-3$ e $\omega$-6 nesses alimentos pode ser o principal responsável pela qualidade do sêmen in natura, uma vez que a fluidez da membrana dos espermatozóides é grandemente relacionada à sua composição lipídica.

Cerolini et al. (2001) verificaram que a diminuição da proporção de ácidos graxos da séria $\omega$-3 em relação aos demais lipídios, resultante da peroxidação durante o armazenamento, reduziu significativamente a qualidade espermática. Seguindo estes estudos, Strzezek et al. (2004) observaram que a inclusão desses ácidos graxos na dieta proporcionou melhoria na qualidade espermática do sêmen in natura. Além disso, verificaram que a proporção entre os níveis de ácido docosahexaenóico (DHA) e de ácido eicosapentaenóico (EPA), ambos $\omega$-3, e destes com ácidos graxos da série $\omega-6$ é importante na manutenção de suas características, por seguirem rotas metabólicas diferenciadas na síntese de outros compostos, em especial prostaglandinas e tromboxanos.

Dessa forma, a inclusão de diferentes tipos de óleo pode ser importante na melhoria das características reprodutivas do macho reprodutor. Com o presente trabalho, objetivou-se avaliar os efeitos da utilização de diferentes fontes de ácidos graxos na ração (óleo de linhaça, óleo comercial $\mathrm{PUFA}^{\circledR}$ e óleo de peixe), como fonte de ácidos linoléicos, $\alpha$-linolênico, eicosapentanóico $\omega-3$ (EPA) e docosahexanóico $\omega$-3 (DHA) sobre a qualidade seminal de suínos.

\section{MATERIAL E MÉTODOS}

O experimento foi conduzido no setor de Suinocultura da Universidade Federal de Lavras (UFLA) durante o período de março a dezembro de 2003.

Foram utilizados 24 suínos híbridos (AGPIC 337), machos inteiros de alta capacidade genética, com peso inicial médio de $152,7 \pm 3,7 \mathrm{~kg}$, alojados em baias individuais em galpão de alvenaria com piso de concreto e cobertura de telhas de cimento amianto. Foi utilizado um delineamento experimental de blocos ao acaso (peso inicial dos animais), num total de seis blocos e quatro tratamentos ( $\mathrm{T} 1$ = controle; $\mathrm{T} 2$ = ração controle com 3,0\% de óleo de linhaça; T3 = ração controle com 3,0\% de óleo PUFA ${ }^{\circledR}$ e T4 = ração controle com 3,0\% de óleo de fígado de peixe), sendo cada animal uma unidade experimental. As rações experimentais isoprotéicas $(13,5 \%)$ e isoenergéticas $(3.350$
Kcal de ED/kg) foram formuladas à base de milho e farelo de soja, segundo as recomendações de Rostagno et al. (2000), sendo suplementadas com minerais e vitaminas, em especial a vitamina $\mathrm{E}$, importante antioxidante de cadeias lipídicas insaturadas de acordo com o NRC (1998) (Tabela 01). As rações foram fornecidas para os animais $(2,0 \mathrm{~kg} / \mathrm{dia})$ até a fase final do experimento (durante 12 semanas), quando atingiram o peso final médio de $189,3 \pm 6,2 \mathrm{~kg}$.

Os animais foram treinados para coleta de sêmen a partir dos cinco meses de idade, com a utilização de um manequim móvel, sendo submetidos a um total de 07 coletas durante o período experimental em intervalos de uma semana. A coleta do sêmen foi realizada na própria baia do animal, através do método da mão enluvada, em frasco graduado, pré-aquecido a $38^{\circ} \mathrm{C}$ e protegido por recipiente isotérmico. A separação da fração gelatinosa do ejaculado foi realizada durante a coleta, através de tripla camada de gaze adaptada ao frasco coletor.

No laboratório, após quatro semanas do início do experimento, foram avaliados semanalmente o volume do ejaculado, a concentração espermática, o número total de células, presença de anormalidades espermáticas, motilidade e vigor espermático, até a décima primeira semana de fornecimento das rações aos animais.

$\mathrm{O}$ volume do ejaculado foi medido diretamente pela graduação do copo coletor, sem a porção gelatinosa.

Para análise de concentração espermática, foi retirada uma amostra de sêmen, com auxílio de uma pipeta automática de $0,01 \mathrm{~mL}$, para ser adicionado a 1,0 mL de solução de $\mathrm{NaCl}$ a $10 \%$, sendo a contagem realizada por meio de hemocitômetro (câmara de Neubauer) na diagonal, com o resultado expresso em número de espermatozóides $/ \mathrm{mm}^{3}$ de sêmen. O número total de células foi calculado após a multiplicação da concentração pelo volume do ejaculado, segundo a metodologia de Martin-Rillo et al. (1996).

Para verificação de anormalidades dos espermatozóides foram utilizados $1,0 \mathrm{~mL}$ de solução de formol citrato, onde foram adicionadas gotas de sêmen até a turvação da solução. Desta solução, homogeneizada, elaborou-se a preparação úmida sem corante para leitura das alterações morfológicas dos espermatozóides, em microscópio de contraste de fase com aumento de 1000 vezes, através da contagem diferencial de 200 células, segundo Scheid (1993). As alterações morfológicas dos espermatozóides, observadas nesse experimento, foram alterações de cabeça, da peça intermediária, da cauda e presença de gota citoplasmática proximal. O total de alterações foi calculado pelo somatório de todas as alterações (maiores e menores) observadas durante a análise. 
TABELA 1 - Composição percentual e bromatológica das rações utilizadas no experimento.

\begin{tabular}{|c|c|c|c|c|}
\hline \multirow{2}{*}{ Ingrediente } & \multicolumn{4}{|c|}{ Tratamentos } \\
\hline & Controle & Linhaça & PUFA $^{\circledR}$ & Peixe \\
\hline Milho & 82,50 & 77,09 & 77,09 & 76,09 \\
\hline F. soja & 14,17 & 14,00 & 14,00 & 14,00 \\
\hline Ó. linhaça & - & 3,00 & - & - \\
\hline Ó. PUFA ${ }^{\circledR}$ & - & - & 3,00 & - \\
\hline Ó. peixe & - & - & - & 3,00 \\
\hline C. calcítico & 0,79 & 0,83 & 0,83 & 0,83 \\
\hline F. bicálcico & 1,55 & 1,49 & 1,49 & 1,49 \\
\hline Sal comum & 0,37 & 0,37 & 0,37 & 0,37 \\
\hline S. vitamínico ${ }^{1}$ & 0,10 & 0,10 & 0,10 & 0,10 \\
\hline Vit. E & 0,01 & 0,01 & 0,01 & 0,01 \\
\hline S. mineral ${ }^{2}$ & 0,10 & 0,10 & 0,10 & 0,10 \\
\hline BHT & 0,02 & 0,02 & 0,02 & 0,02 \\
\hline Caulim & 0,39 & 3,00 & 3,00 & 4,00 \\
\hline Total & 100,0 & 100,0 & 100,0 & 100,0 \\
\hline $\mathrm{PB}(\%)^{3}$ & 13,50 & 13,50 & 13,50 & 13,50 \\
\hline $\mathrm{ED}(\mathrm{Kcal} / \mathrm{Kg})^{3}$ & 3350 & 3350 & 3350 & 3350 \\
\hline Ác. oleico $(\%)^{4}$ & 0,00 & 0,67 & 0,67 & 0,51 \\
\hline Ác. linoléico $(\%)^{4}$ & 0,00 & 0,62 & 0,67 & 0,06 \\
\hline Ác. linolênico $(\%)^{4}$ & 0,00 & 1,00 & 0,92 & 0,06 \\
\hline $\mathrm{EPA}^{3}$ & - & - & 0,03 & 0,27 \\
\hline $\mathrm{DHA}^{3}$ & - & - & 0,03 & 0,03 \\
\hline Cálcio total $(\%)^{3}$ & 0,76 & 0,76 & 0,76 & 0,76 \\
\hline Fósforo disp $(\%)^{4}$ & 0,38 & 0,38 & 0,38 & 0,38 \\
\hline
\end{tabular}

${ }^{1}$ Suplemento vitamínico contendo: vitamina A, 250.000 UI; vitamina D3, 42.000 UI; vitamina E, 500 mg; vitamina K3, 67 mg; vitamina B1, $50 \mathrm{mg}$ : vitamina B2, $100 \mathrm{mg}$; vitamina B6, $67 \mathrm{mg}$; vitamina B12, $400 \mathrm{mcg}$; niacina, $667 \mathrm{mg}$; pantotenato de cálcio, $417 \mathrm{mg}$; colina, $10.000 \mathrm{mg}$; antioxidante, $2.500 \mathrm{mg}$.

${ }^{2}$ Suplemento mineral contendo: cálcio, $245 \mathrm{~g}$; fósforo, $75 \mathrm{~g}$; ferro, $2.333 \mathrm{mg}$; cobre, $333 \mathrm{mg}$; manganês; $1.333 \mathrm{mg}$; Iodo, $20 \mathrm{mg}$; selênio, $5 \mathrm{mg}$; zinco, $2.667 \mathrm{mg}$; flúor, $1 \mathrm{~g}$; cobalto, 15,33 mg.

${ }^{3}$ Análise realizada no Laboratório de Nutrição do Departamento de Zootecnia da UFLA.

${ }^{4}$ Valores segundo Rostagno et al. (2000).

A motilidade e o vigor foram avaliados segundo escalas de 0 a 100 e 0 a 5 , respectivamente, segundo metodologia proposta por Scheid (1993). Para tal análise, retirou-se uma gota de sêmen imediatamente após a coleta, sendo esta colocada sobre lâmina, recoberta por lamínula previamente aquecida à temperatura de $37^{\circ} \mathrm{C}$, para leitura ao microscópio óptico (40x). As avaliações foram realizadas em triplicata, independentemente, por dois avaliadores e expressas em percentual de células móveis da amostra.

Para as variáveis de volume, concentração e número total de células espermáticas adotou-se um delineamento em blocos casualizados em esquema fatorial $4 \times 7$ (4 tratamentos e 7 semanas de avaliação), com seis repetições, sendo os blocos constituídos pelo peso dos animais. Para as análises, foi utilizado o procedimento GLM (General Linear Methods) do programa estatístico SAS versão 6.12 (SAS PROGRAM, 1997) após a transformação dos dados (raiz quadrada), e submetidas ao teste Tukey a 5\% de probabilidade.

Para as variáveis de alterações morfológicas (cabeça, peça intermediária, cauda, presença de gota citoplasmática proximal e total de alterações), motilidade progressiva e vigor espermático foi aplicado o teste não-paramétrico de Kruskall-Wallis - programa SAEG 5.0 (UFV, 2002).

\section{RESULTADOS E DISCUSSÕES}

Os valores obtidos para volume do ejaculado, concentração espermática e número total de células no ejaculado estão apresentados na Tabela 2. 
TABELA 2 - Valores médios para volume ( $\mathrm{ml}$ ), concentração (espermatozóides $/ \mathrm{mm}^{3}$ ) e número total de células nos ejaculados de reprodutores suínos recebendo diferentes fontes de óleo na dieta.

\begin{tabular}{|c|c|c|c|}
\hline Tratamentos & $\begin{array}{c}\text { Volume do ejaculado } \\
(\mathrm{ml})\end{array}$ & $\begin{array}{c}\text { Concentração }\left(\times 1^{6}\right. \\
\left.\text { sptz/mm }^{3}\right)\end{array}$ & $\begin{array}{l}\text { Número Total de } \\
\text { Células }\left(\mathbf{x 1 0}^{9}\right)\end{array}$ \\
\hline Controle & $166,80 \mathrm{~b}$ & 3,41 & $48,79 \mathrm{~b}$ \\
\hline Óleo de linhaça & $153,45 \mathrm{~b}$ & 3,50 & $43,56 \mathrm{~b}$ \\
\hline PUFA & $218,97 \mathrm{a}$ & 2,92 & $74,80 \mathrm{a}$ \\
\hline Óleo de peixe & $168,71 \mathrm{~b}$ & 3,28 & $51,12 \mathrm{~b}$ \\
\hline $\mathrm{CV}(\%)$ & 53,14 & 49,89 & 14,93 \\
\hline
\end{tabular}

Médias seguidas de letras distintas na coluna diferem pelo teste de Tukey $(\mathrm{P}<0,05)$.

O volume do ejaculado e o número total de células foram significativamente maiores $(\mathrm{P}<0,01)$ para o tratamento que recebeu o óleo comercial PUFA ${ }^{\circledR}$, porém a concentração dos ejaculados mostrou-se semelhante entre os tratamentos. Resultados similares foram obtidos por Murgas (1999), ao adicionarem óleo de soja na ração de reprodutores em relação à dieta controle. Neste trabalho, o autor associou esse aumento a um maior diâmetro dos túbulos seminíferos observados no grupo de animais que recebeu a ração suplementada com óleo. De acordo com Rooke et al. (2001), a relação entre ácidos graxos $\omega$-6 e $\omega$-3 nestas dietas é de 6:1 e não há cadeias longas de ácidos graxos poliinsaturados da série $\omega-3$.

Por outro lado, alguns trabalhos mostram efeitos significativos da utilização de fontes lipídicas compostas basicamente de ácidos graxos da série $\omega$-3 em relação aos animais não suplementados. Strzezek et al. (2004) associaram aumento na concentração espermática dos ejaculados de varrões que receberam suplemento dietético específico (Prosperm ${ }^{\circledR}$ ), composto de DHA, vitamina E e selênio. Resultados semelhantes foram obtidos por Maldjian et al. (2005), ao suplementarem dietas de varrões com óleo de peixe, em relação à dieta controle. Estes trabalhos observaram aumento dos níveis de DHA e diminuição dos níveis de EPA no sêmen dos animais que receberam a suplementação na dieta.

De acordo com Rooke et al. (2001), o ácido graxo DHA ù-3 desempenha uma função essencial promovendo ótima fertilidade, principalmente em humanos e que reduções significativas deste ácido graxo na fração lipídica dos espermatozóides têm correlação não só com reduções na concentração espermática, mas também na motilidade progressiva e morfologia normal dos espermatozóides.

No presente trabalho, embora não tenha havido diferenças significativas com relação a estes parâmetros entre a utilização de óleo de peixe em relação à dieta controle, a suplementação da dieta com óleo comercial PUFA $^{\circledR}$ mostrou melhores resultados no que diz respeito ao aumento do volume do ejaculado. Associado a isto, a manutenção da concentração espermática entre os tratamentos, indica maior produção de líquido seminal pelas glândulas acessórias e maior produção de células produzidas nos túbulos seminíferos.

Os valores obtidos para alterações morfológicas dos espermatozóides encontram-se na Tabela 3.

Dentre as anormalidades espermáticas avaliadas, houve efeito significativo apenas para alterações de cauda $(\mathrm{P}<0,05)$, sendo o óleo de peixe o que proporcionou maior índice de alterações. Maldjian et al. (2005) não observaram diferenças significativas ao utilizarem óleo de peixe na dieta de varrões. Segundo esses autores, a utilização desse óleo é dependente da adição concomitante de substâncias antioxidantes, das quais a vitamina $\mathrm{E}$ e o selênio são primordiais. Strzezek et al. (2004), apesar de não observarem diferenças significativas na porcentagem de células anômalas, observaram maior atividade da enzima superóxido dismutase (SOD) e produção de malondialdeído (MDA) no ejaculado de varrões que receberam suplementação com Prosperm ${ }^{\circledR}$. De acordo com Aitken et al. (1996), estas substâncias são indicadoras de atividade peroxidativa dos ácidos graxos poliinsaturados, e que sua intensidade aumenta na presença de ácidos graxos da série $\omega-3$.

Dessa forma, os maiores valores de alterações de cauda observados no presente experimento pode ser devido à falta de suplementação de selênio na dieta, juntamente com a vitamina E. Segundo Chatterjee \& Gagnon (2001), a maior produção de substâncias resultantes da peroxidação lipídica ocorre na cauda, em função da maior concentração de mitocôndria na peça intermediária e conseqüentemente do maior fluxo de oxigênio nas proximidades dessa região espermática. 
Com relação ao total de alterações, resultados semelhantes foram obtidos por Murgas (1999) e Strzezek et al. (2004). Este resultado sugere que a adição de antioxidante (vitamina E) nas dietas do presente experimento dificultaram a peroxidação dos lipídios de membrana de uma forma geral, não permitindo a detecção de diferenças de anormalidades totais entre os tratamentos.

Os parâmetros de motilidade espermática progressiva e vigor espermático encontram-se na Tabela 4.

Com relação à motilidade espermática, não houve diferenças significativas entre os tratamentos $(\mathrm{P}>0,05)$, porém houve melhora no vigor quando se utilizou óleo de peixe na ração $(\mathrm{P}<0,05)$. Rooke et al. (2001), fornecendo $3 \%$ de óleo de atum na dieta de varrões observaram aumentos significativos da motilidade progressiva, sem, no entanto, mencionarem o vigor. Sudheera et al. (1997) consideram que os ácidos graxos poliinsaturados $\omega$-3 da dieta podem influenciar a fluidez das membranas e a atividade de enzimas necessárias para a produção de energia e de muitas funções de receptores dependentes de lipídeos-proteína. No presente trabalho, apesar dos resultados mostrarem que a motilidade dos espermatozóides não sofreu melhora significativa, a intensidade de movimentação destes representada pelo vigor aumentado significativamente pode melhorar a fertilidade destes animais recebendo o óleo de peixe em suas dietas. Além disso, o aumento das anomalidades de cauda observado anteriormente não interferiu na movimentação espermática observada no sêmen in natura.

TABELA 3 - Valores médios de alterações morfológicas de cabeça (\%), de peça intermediária (\%), de cauda (\%), presença de gota citoplasmática proximal (\%) e total de alterações espermáticas (\%) no sêmen de reprodutores recebendo diferentes fontes de óleo na dieta ${ }^{1}$.

\begin{tabular}{lccccc}
\hline Tratamentos & $\begin{array}{c}\text { Alterações } \\
\text { de cabeça }\end{array}$ & $\begin{array}{c}\text { Alterações de Peça } \\
\text { Intermediária }\end{array}$ & $\begin{array}{c}\text { Alterações } \\
\text { de Cauda }\end{array}$ & $\begin{array}{c}\text { Presença de Gota } \\
\text { Citoplasmática } \\
\text { Proximal }\end{array}$ & $\begin{array}{c}\text { Total de } \\
\text { Alterações }\end{array}$ \\
\hline Controle & 3,31 & 0,24 & $1,69 \mathrm{~b}$ & 2,05 & 10,20 \\
Óleo de linhaça & 2,09 & 0,34 & $4,14 \mathrm{~b}$ & 1,97 & 11,14 \\
PUFA & 2,29 & 0,23 & $3,11 \mathrm{~b}$ & 0,74 & 9,57 \\
Óleo de peixe & 1,91 & 0,14 & $5,83 \mathrm{a}$ & 1,63 & 12,23 \\
\hline P & NS & NS & $<0,05$ & NS & NS \\
\hline
\end{tabular}

${ }^{1}$ Médias seguidas de letras distintas na coluna diferem pelo teste de Kruskall-Wallis $(\mathrm{P}<0,05)$.

TABELA 4 - Valores médios para motilidade (\%) e vigor do sêmen de reprodutores suínos recebendo diferentes fontes de óleo na dieta.

\begin{tabular}{lcc}
\hline Tratamentos & Motilidade & Vigor \\
\hline Controle & 80,71 & $3,81 \mathrm{ab}$ \\
Óleo de linhaça & 79,88 & $3,90 \mathrm{ab}$ \\
PUFA & 80,36 & $3,74 \mathrm{~b}$ \\
Óleo de peixe & 84,29 & $4,26 \mathrm{a}$ \\
\hline $\mathrm{P}$ & $\mathrm{NS}$ & $<0,05$ \\
\hline
\end{tabular}

${ }^{1}$ Médias seguidas de letras distintas na coluna diferem pelo teste de Kruskall-Wallis $(\mathrm{P}<0,05)$. 


\section{CONCLUSÃO}

O uso de óleo comercial PUFA ${ }^{\circledR}$ nas rações de varrões demonstrou ser mais eficiente nas avaliações do sêmen in natura para a produção de células espermáticas. Para viabilidade dos espermatozóides, o óleo de peixe apresentou melhores resultados, apesar do maior número de alterações de cauda observado.

\section{REFERÊNCIAS BIBLIOGRÁFICAS}

AITKEN, R. J.; BUCKINGHAM, D. W.; CARRERAS, A.; IRVINE, D. S. Superoxide dismutase in human sperm suspensions: relationship with cellular composition, oxidative stress and sperm function. Free Radical Biology \& Medicine, [S.1.], v. 21, p. 495-504, 1996.

CEROLINI, S.; MALDJIAN, A.; PIZZI, F.; GLIOZZI, T. M. Changes in sperm quality and lipid composition during cryopreservation of boar semen. Reproduction, [S.l.], v. 121, p. 395-401, 2001.

CHATTERJEE, S.; GAGNON, C. Production of reactive oxygen species by spermatozoa undergoing cooling, freezing, and thawing. Molecular Reproduction Development, [S.1.], v. 59, p. 451-458, 2001.

MALDJIAN, A.; PIZZI, F.; GLIOZZI, T.; CEROLINI, S.; PENNY, P.; NOBLE, R. Changes in sperm quality and lipid composition during cryopreservation of boar sêmen. Theriogenology, Worburn, v. 63, n. 2, p. 411-421, 2005.

MARTIN-RILLO, S.; MARTINEZ, E.; GARCIA-ARTIGA, C.; DE-ALBA, C. Boar semen evaluation in practice. Reproduction Domestics Animal, [S.1.], v. 31, n. 4, p. 519526, 1996.

MURGAS, L. D. S. Desempenho reprodutivo de varrões híbridos alimentados com rações suplementadas com óleo de soja como fonte de ácidos graxos. 1999. 111 p. Tese
(Doutorado) - Universidade Federal de Lavras, Lavras, 1999.

NATIONAL RESEACH COUNCIL. Nutrient requeriments of swine. 10. ed. Washington: National Academy of Science, 1998. $189 \mathrm{p}$.

ROOKE, J. A.; SINCLAIR, A. G.; EDWARDS, S. A. Effects of feeding tuna oil on the lipid composition of pig spermatozoa and in vitro characteristics of semen. Reproduction, [S.1.], v. 121, n. 2, p. 315-322, 2001.

ROSTAGNO, H. S.; SILVA, D. L.; COSTA, P. M. A.; FONSECA, J. B.; SOARES, P. R. Composição de alimentos e exigências nutricionais de aves e suínos: tabelas brasileiras. Viçosa: UFV, 2000. 60 p.

SAS PROGRAM. User guide for personal computer. Cary, 1997.

SCHEID, I. R. Manual de inseminação artificial de suínos: procedimentos e métodos no laboratório. Concórdia: CNPSA-EMBRAPA, 1993. 48 p.

STRZEZEK, J.; FRASER, L.; KUKLINSKA, M.; DZIEKONSKA, A.; LECEWICZ, M. Effects of dietary supplementation with polyunsaturated fatty acids and antioxidants on biochemical characteristics of boar semen. Reproductive Biology, [S.1.], v. 4, n. 3, p. 271-287, 2004.

SUDHEERA, S. D.; JAMES, W. L.; FALCONER, L.; GARG, M. L. Prevention of cardiac arrhytmia by dietary (n-3) polyunsaturated fatty acids and their mechanism of action. The Journal of Nutrition, Philadelphia, v. 127, n. 4, p. 383393, 1997.

UNIVERSIDADE FEDERAL DE VIÇOSA. Sistema de Análises Estatísticas e Genéticas: manual do usuário. Versão 5.0. Viçosa, 1992. 59 p. 